\title{
Erratum to: Feelings of loneliness among adults with mental disorder
}

\author{
Howard Meltzer • Paul Bebbington • \\ Michael S. Dennis • Rachel Jenkins • \\ Sally McManus • Traolach S. Brugha
}

Published online: 4 November 2014

(c) Springer-Verlag Berlin Heidelberg 2014

\section{Erratum to: Soc Psychiatry Psychiatr Epidemiol DOI 10.1007/s00127-012-0515-8}

Unfortunately, in the article's abstract the critical word 'not' is missing from the results statement: "Inserting measures of formal and informal social participation and perceived social support into the logistic regression models did significantly reduce these odds ratios."

Please find the correct abstract below:

\begin{abstract}
Purpose Loneliness can affect people at any time and for some it can be an overwhelming feeling leading to negative thoughts and feelings. The current study, based on the Adult Psychiatric Morbidity Survey in England, 2007, quantified the association of loneliness with a range of specific mental disorders and tested whether the relationship was influenced
\end{abstract}

The online version of the original article can be found under doi:10.1007/s00127-012-0515-8.

\section{H. Meltzer}

Department of Health Sciences, College of Medicine,

Biological Sciences and Psychology, University of Leicester,

22-28 Princess Road West, Leicester LE1 6TP, UK

P. Bebbington

Emeritus Professor of Social and Community Psychiatry,

UCL Department of Mental Health Sciences, 2nd Floor,

Charles Bell House, 67-73 Riding House Street,

W1W 7EJ London, UK

e-mail: P.Bebbington@ucl.ac.uk

\section{S. Dennis}

The School of Medicine, Swansea University,

Singleton Park, Swansea SA2 8PP, UK

e-mail: m.s.dennis@swansea.ac.uk by formal and informal social participation and perceived social support.

Methods Using a random probability sample design, 7,461 adults were interviewed in a cross-sectional national survey in England in 2007. Common Mental Disorders were assessed using the revised Clinical Interview Schedule; the diagnosis of psychosis was based on the administration of the Schedules of the Clinical Assessment of Neuropsychiatry, while loneliness was derived from an item in the Social Functioning Questionnaire.

Results Feelings of loneliness were more prevalent in women $(\mathrm{OR}=1.34,95 \%$ CI $1.20-1.50, P<0.001)$ as well as in those who were single $(\mathrm{OR}=2.24,95 \% \mathrm{CI}$ 1.96-2.55, $P<0.001$ ), widowed, divorced or separated $(\mathrm{OR}=2.78,95 \%$ CI $2.38-3.23, P<0.001)$, economically inactive $(\mathrm{OR}=1.24, \quad 95 \%$ CI 1.11-1.44, $P=0.007)$, living in rented accommodation $(\mathrm{OR}=1.73$, $95 \%$ CI $1.53-1.95, P<0.001)$ or in debt $(\mathrm{OR}=2.47$, $95 \%$ CI $2.07-1.50, P<0.001)$. Loneliness was associated with all mental disorders, especially depression

\section{R. Jenkins}

Institute of Psychiatry, King's College London,

De Crespigny Park, Denmark Hill, London SE1 5AF, UK

e-mail: rachel@olan.org

\section{S. McManus}

National Centre for Social Research,

35 Northampton Square, London EC1V 0AX, UK

e-mail: Sally.McManus@natcen.ac.uk

\section{T. S. Brugha $(\square)$}

Department of Health Sciences, University of Leicester,

New Academic Unit, Leicester General Hospital,

Gwendolen Road, Leicester LE5 4PW, UK

e-mail: tsb@le.ac.uk 
$(\mathrm{OR}=10.85,95 \%$ CI 7.41-15.94, $P<0.001)$, phobia $(\mathrm{OR}=11.66,95 \% \mathrm{CI} 7.01-19.39, P<0.001)$ and OCD $(\mathrm{OR}=9.78,95 \%$ CI 5.68-16.86, $P<0.001)$. Inserting measures of formal and informal social participation and perceived social support into the logistic regression models did not significantly reduce these odds ratios.
Conclusion Increasing social support and opportunities for social interaction may be less beneficial than other strategies emphasising the importance of addressing maladaptive social cognition as an intervention for loneliness. 